\title{
UNUSUAL INITIAL MANIFESTATION OF RHEUMATOID ARTHRITIS: SCLERITIS IN A PATIENT WITHOUT JOINT DAMAGE
}

Viviane Leal Novais ${ }^{1, \star}$, Gustavo Luiz Behrens Pinto ${ }^{1}$, Renata Borges de Lima ${ }^{1}$, Maria de Lourdes Castro de Oliveira Figueiroa ${ }^{1}$, Alisson Regis de Santana ${ }^{1}$, Mariana Oliveira Miranda ${ }^{1}$, Victor Pereira Mattos ${ }^{1}$, Mittermayer Santiago ${ }^{1}$

1.Universidade Federal da Bahia, Salvador (BA), Brazil.

*Corresponding author: vivilnovais@gmail.com

\section{BACKGROUND}

Rheumatoid arthritis (RA) is an inflammatory autoimmune systemic disease that causes joint damage of hands, feet, wrists, and knees, and also can develop extra-articular manifestations, conferring a greater severity and a worsening prognosis. In this text, ocular involvement, commonly scleritis and episcleritis, can be expected in a patient with long-term active RA. The purpose of this report is to describe a case in which severe bilateral scleritis was the first manifestation of RA, without signs of joint inflammation.

\section{CASE REPORT}

A 60-year-old female was admitted to our hospital complaining of bilateral ocular pain with redness, photophobia, tearing, and reduced visual acuity for the last six months. In the same period, she had symmetrical polyarthralgia of small joints of the hands, morning stiffness for $30 \mathrm{~min}$, without phlogistic signs, that spontaneously improved without any specific treatment. Physical examination revealed intense bilateral conjunctival hyperemia (Figure 1) and thinning of the sclera in the upper region of the left eyeball (Figure 2). She also had subcutaneous, fibroelastic and painless nodules on the extensor surface of the forearms, suggestive of rheumatoid nodules (Figure 3). She did not have synovitis or arthritis. On ophthalmologic examination, nodular scleritis was evidenced in the right eye and necrotizing scleritis in the left eye. Laboratory tests showed acute phase markers elevated and antiCCP in high titers (anti-CCP was $139 \mathrm{U} / \mathrm{mL}$, reference less than $5 \mathrm{U} / \mathrm{mL}$ ). Hand and wrist radiography was normal. Therefore, ocular lesions were considered a severe extra-articular manifestation of RA. The patient received pulse therapy with methylprednisolone and cyclophosphamide, followed by oral prednisone $1 \mathrm{mg} / \mathrm{kg}$, in addition to a corneo-palpebral surgical approach to the thinning area of the conjunctiva of the left eye. After pulse therapy, the patient evolved with partial improvement of her visual acuity and hyperemia and absence of eye pain.

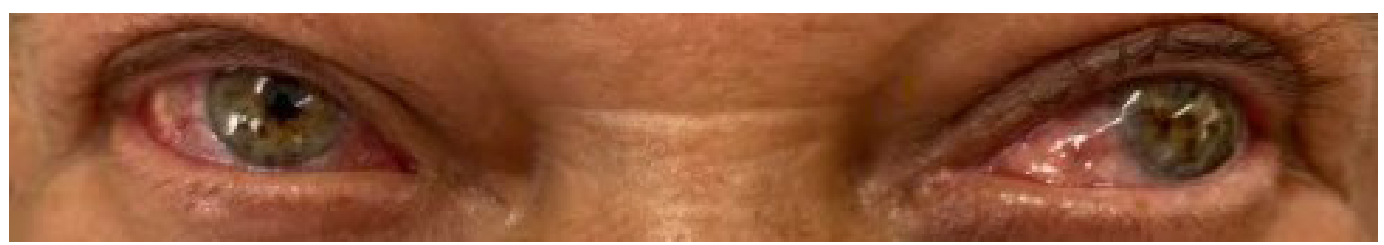

Figure 1. Bilateral conjunctival hyperemia.

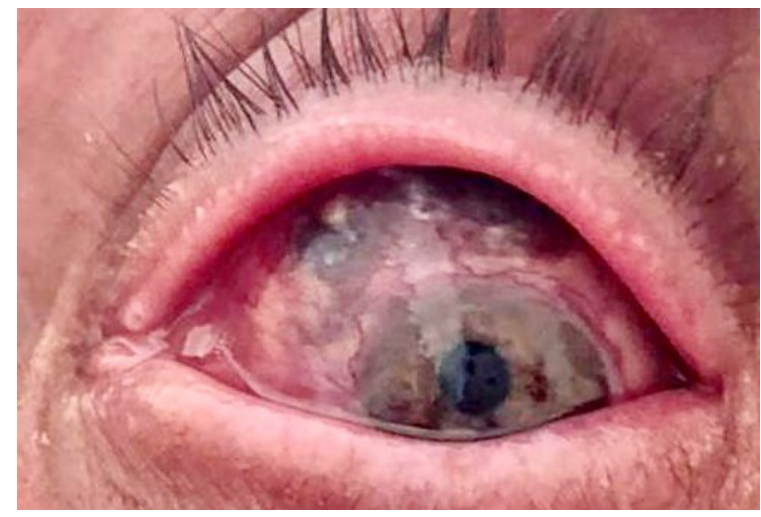

Figure 2. Thinning of the sclera. 


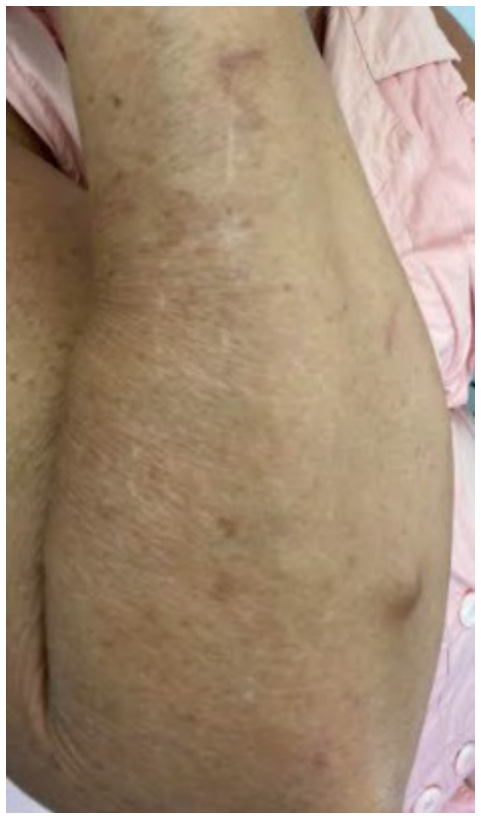

Figure 3. Subcutaneous and fibroelastic nodules on the extensor surface of the forearms.

\section{CONCLUSION}

Although the presence of nodular or necrotizing scleritis is uncommon, it is potentially serious and can progress with dissociation of the joint involvement, making the diagnosis difficult. Due to its inflammatory and autoimmune nature, oral or intravenous corticosteroids, methotrexate and cyclophosphamide can change the course of the disease. Biological agents such as infliximab, adalimumab and rituximab have been effective in refractory cases of necrotizing scleritis. Early recognition is essential for the condition to be promptly treated. Clinicians need to be aware of the possibility of associated rheumatologic disease, especially RA, in severe cases of scleritis.

\section{KEYWORDS}

Arthritis, Rheumatoid, Scleritis, Necrotizing, Manifestation, Yes. 